DE

M E D I C I N A

T R O P I C A L

$\mathrm{DE}$

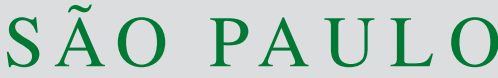

JOURNAL OF THE SÃO PAULO INSTITUTE OF TROPICAL MEDICINE

${ }^{1}$ Escola de Saúde Pública do Ceará,

Fortaleza, Ceará, Brazil

${ }^{2}$ Hospital São José de Doenças Infecciosas, Fortaleza, Ceará, Brazil

${ }^{3}$ Fundação Oswaldo Cruz, Fortaleza, Ceará, Brazil

${ }^{4}$ Universidade Federal do Ceará, Faculdade de Medicina, Departamento de Saúde Comunitária, Fortaleza, Ceará, Brazil

Correspondence to: Francisco José Cândido da Silva

Hospital São José de Doenças Infecciosas, Rua Nestor Barbosa, 315, Parquelandia, CEP 60455-610, Fortaleza, CE, Brazil

E-mail: franciscojose.candido @ gmail.com

Received: 26 November 2021

Accepted: 18 January 2022

\section{COVID-19-associated meningoencephalitis in a Brazilian patient: case report and literature review}

\author{
Francisco José Cândido da Silva ${ }^{1,2}$, Luís Arthur Brasil Gadelha Farias ${ }^{1,2}$, \\ Pablo Eliack Linhares de Holanda ${ }^{\circledR}$, Fernanda Remígio Nunes ${ }^{\circledR}$, Fábio \\ Miyajima ${ }^{\circledR 3}$, Lisandra Serra Damasceno ${ }^{\circledR 2,4}$
}

\section{ABSTRACT}

The global pandemic of COVID-19 is caused by the novel coronavirus SARS-CoV-2, which often causes flu-like symptoms and can progress to severe respiratory illness. Thus, as the disease spreads, COVID-19 cases have multiplied across the world, and manifestations involving multiple systems have been described. We report a case of COVID-19-associated meningoencephalitis in a Brazilian male patient who presented with seizures and altered mental status. To the best of our knowledge, this is the first reported case of COVID-19-associated meningoencephalitis in Brazil. COVID-19-associated meningoencephalitis is a rare manifestation of this viral infection and clinicians should be aware of this possible complication.

KEYWORDS: SARS-CoV-2. COVID-19. Meningoencephalitis. Coronavirus.

\section{INTRODUCTION}

The novel coronavirus disease or COVID-19 is caused by SARS-CoV-2, another RNA virus SARS-CoV that emerged in Wuhan, China, in 2019 ${ }^{1}$. Currently, since the World Health Organization officially declared a pandemic state on March 11, 2020, SARS-CoV-2 infection still affects millions of people worldwide ${ }^{2}$. The most common clinical manifestations of COVID-19 are flu-like symptoms, pneumonia and the acute respiratory distress syndrome (ARDS) ${ }^{3}$. However, a wide variety of symptoms related to different organs and systems have been reported. The more affected systems after the respiratory tract are $\operatorname{cardiac}^{4}$, central nervous system $(\mathrm{CNS})^{5}$, gastrointestinal and renal ${ }^{6}$. Regarding the neurological involvement, the more commonly reported symptoms are headache, dysgeusia and hyposmia or anosmia. Severe neurological impairment such as encephalitis, meningitis, Guillain-Barré syndrome and vascular events have been described, but they are rare ${ }^{7}$. Several pathological mechanisms have been proposed, such as the direct action of SARS-CoV-2 in the CNS, viral dissemination through neuronal pathways, hematogenic invasion, immune-mediated lesions due to the cytokine storm syndrome and CNS-related hypoxic lesions ${ }^{7}$. Herein, we report a case of COVID-19-associated meningoencephalitis in a male patient hospitalized during the first wave of COVID-19 in Brazil. In addition, we performed a literature review using the PubMed database and the descriptors meningitis and COVID-19, or meningoencephalitis and COVID-19. This case report is part of a cohort study approved by the Research Ethics Committee of Hospital Sao José de Doenças Infecciosas (HSJ) (CAAE N $\left.{ }^{\circ} 35017820.1 .0000 .5044\right)$. An informed consent to publish the patient's clinical data was provided by the patient. 


\section{CASE REPORT}

A 68-year-old Brazilian man sought the emergency department (ED) in July 11, 2020, presenting with generalized clonic seizures, nausea, vomiting and altered mental status that started the day before and fever two days before admission. He had no respiratory symptoms. Upon physical examination, the patient was afebrile, disoriented, had a heart rate of $89 \mathrm{bpm}$ and a respiratory rate of $20 \mathrm{rpm}$, normal vesicular breath sounds in both lungs, accompanied by nuchal rigidity, negative Brudzinski , Kernig and Lasegue signs. The cranial computed tomography (CT) findings were normal. Chest CT findings were unremarkable. Cerebrospinal fluid (CSF) analysis revealed 23 cells $/ \mathrm{mm}^{3}$ (89\% lymphocytes, $6 \%$ monocytes and $5 \%$ neutrophils), protein $52 \mathrm{mg} / \mathrm{dL}$, and glucose $58 \mathrm{mg} / \mathrm{dL}$. The CSF gram, fungal stains and bacterial cultures were negative. Intravenous acyclovir was administered. Multiplex PCR (FilmArray Meningitis Encephalitis Panel) of CSF was negative for Streptococcus pneumoniae, Neisseria meningitidis, Haemophilus influenzae, Herpesvirus, Varicella-zoster virus, Cytomegalovirus and Cryptococcus spp. After the results of multiplex PCR, the antiviral administration was discontinued. SARS-CoV-2 was detected by qPCR in a nasopharyngeal and oropharyngeal swab using the Charité, Berlinprotocol for SARS-CoV-2 (E) Bio- Manguinhos kit ${ }^{8}$. Later, SARS-CoV-2 RNA was also amplified in CSF specimens using the $\mathrm{CDC}$ protocol ${ }^{9}$. Cranial magnetic resonance imaging (MRI) showed leptomeningeal enhancement and diffuse alteration of the bilateral periventricular white matter suggestive of encephalitis (Figure 1). On day 9 of hospitalization, although the patient presented with neurological improvement, he developed new episodes of fever, cough and purulent sputum. Chest radiography revealed a pulmonary consolidation. Chest $\mathrm{CT}$ revealed bilateral pleural effusion and a right lobe

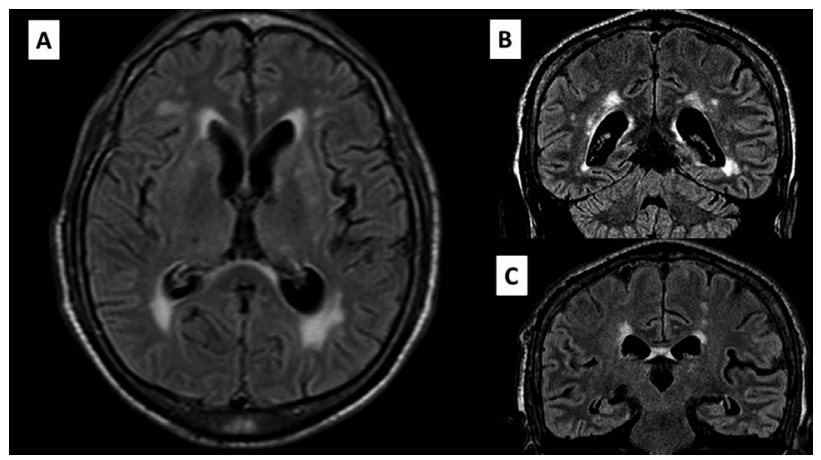

Figure 1 - Brain MRI with areas of hyperintensity in T2w-FLAIR on the bilateral periventricular white matter and leptomeningeal enhancement: (A) Sagittal plane; (B) and (C) Coronal plane. $\mathrm{MRI}=$ magnetic resonance imaging; $\mathrm{T} 2 \mathrm{w}-\mathrm{FLAIR}=\mathrm{T} 2$-weighted fluid-attenuated inversion recovery. consolidation without ground-glass opacities. A 10-day regimen of meropenem and vancomycin was administered. He presented with clinical improvement and was discharged after 20 days of hospitalization.

\section{DISCUSSION}

The neurological findings related to SARS-CoV-2 infection and the pathogenesis of the disease in the CNS are not completely understood. Previous studies in autopsies revealed the presence of the virus in the CSF and brain parenchyma, which may suggest its tropism and ability to penetrate the $\mathrm{CNS}^{10,11}$.

The two main hypotheses are based on neurotropism by the direct invasion of SARS-CoV-2 in the CNS and indirect mechanisms mediated by the cytokine storm. In a study of post-mortem brain biopsies from patients with COVID-19, activation of microglia and infiltration of cytotoxic $\mathrm{T}$ lymphocytes were observed, mainly in the brainstem and cerebellum. Microglia express the CD68 marker intensely, causing an increase in the phagocytic activity ${ }^{12}$. Among the main pathways that the virus can reach the CNS is the hematogenous pathway, which has already been described for other coronaviruses. In addition, viral particles have been found in the capillary endothelium and frontal lobe neurons in autopsies, corroborating this statement. However, in the neuronal pathway, the virus infects nerve endings and migrates across synapses to reach the $\mathrm{CNS}^{7,10,11}$.

The presence of neurological symptoms in COVID-19 usually occurs in more than one-third of patients ${ }^{7}$. The olfactory nerve is the main affected neuronal via due to its proximity to the nasal cavity, the primary site of SARS-CoV-2 infection. The finding of hyposmia or anosmia in the early stages of the disease is frequently observed in many patients ${ }^{12}$, showing that SARS-CoV-2 may have a tendency for neuro-invasion ${ }^{10-12}$.

Neurological syndromes have also been associated with SARS-CoV-2 infection. Encephalitis, meningitis, acute disseminated encephalomyelitis, Guillain-Barré syndrome and acute stroke have been reported ${ }^{6,7,13}$. The first case of COVID-19-associated meningoencephalitis was described in a 24-year-old man that had intense headache and fever ${ }^{5}$. The MRI revealed hiperintensity along the wall of the inferior horn in the right lateral ventricle, as well as hyper intense signal changes in the right mesial temporal lobe and hippocampus 5 .

Since then, other cases have been reported worldwide, but still represent few cases compared to the large pandemic scale $^{5,13-20}$. Table 1 shows all reported cases of meningitis and meningoencephalites in PubMed database until September 2021. Positive RT-PCR in CSF seems to be a rare 


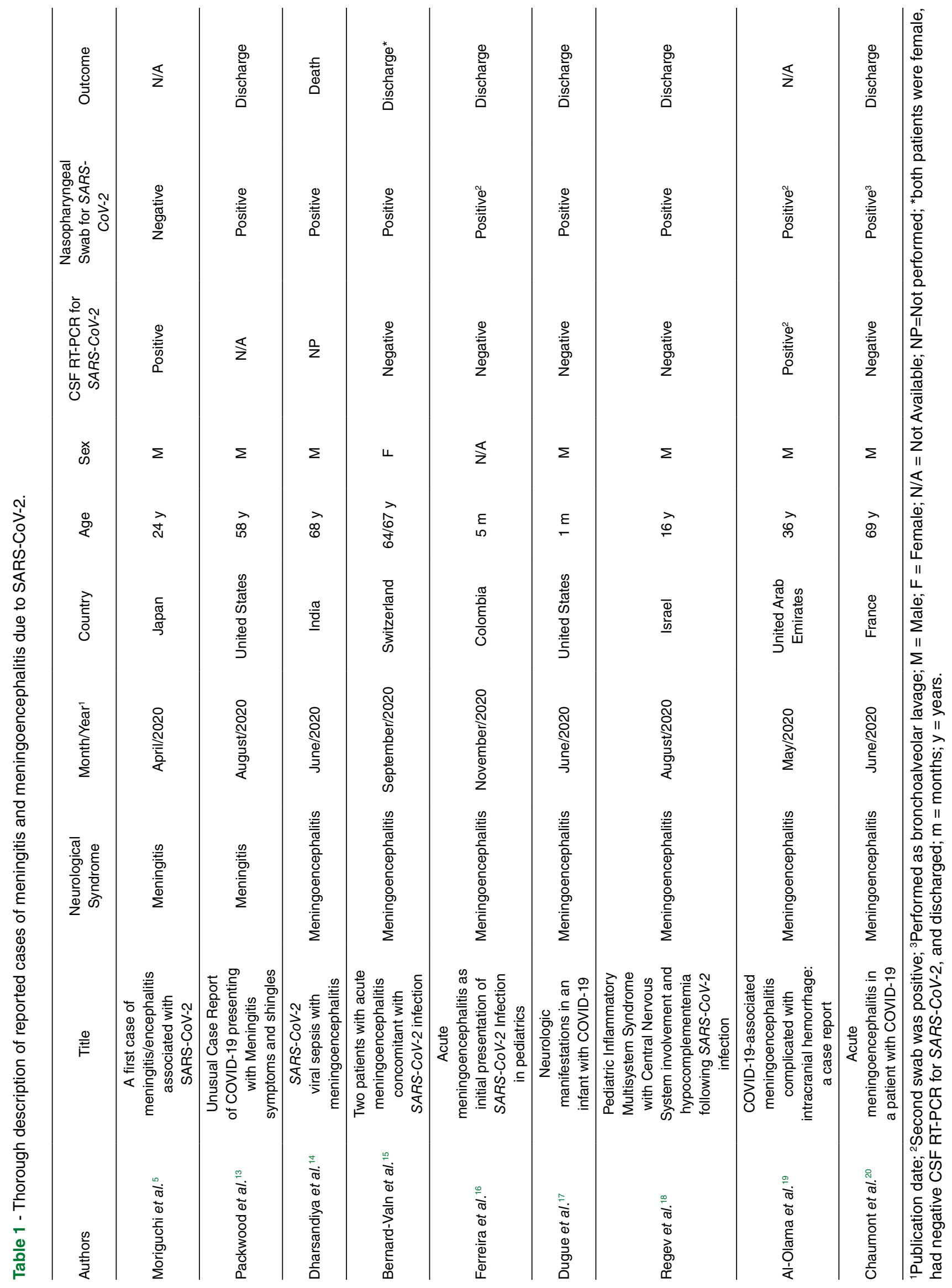


finding. Furthermore, the sensitivity and specificity of RTPCR in CSF are unknown ${ }^{5}$. We only found two cases with positive RT-PCR for SARS-CoV-2 in CSF in the literature review. Herein, we describe the first case of SARS-COV-2 detected in CSF in Brazil.

In a recent systematic review of 61 cases, Mondal et $a l .{ }^{12}$ found that confusion, disorientation and altered mental status were observed in $22.22 \%$ of cases. Kernig's and Lasegue's signs were absent, although nuchal rigidity was present in $9.25 \%^{12}$. In this case, the main symptoms were seizures and altered mental status. Signals of meningism were not detected.

Viral meningoencephalitis usually causes leptomeningeal inflammation that may be present adjacent to the subpial cortical lesions. Lymphocytic pleocytosis and CSF protein levels are typically observed in viral meningoencephalitis ${ }^{7,12}$. Previous studies revealed that MRI without abnormalities occurs in the majority of cases. However, the most common abnormality reported was T2/FLAIR hyperintensity affecting the temporal lobes, which may occur in other viral conditions $^{7,12}$. Electroencephalography (EEG) may reveal non-specific findings such as focal epileptiform discharges and generalized slowness of the waves ${ }^{12}$.

In our case, the diagnosis of COVID-19-associated meningoencephalitis was diagnosed based on clinical symptoms, CSF analysis and MRI findings. EEG was unavailable in our service and there was also a high risk of SARS-CoV-2 transmission during the patient's transportation.

\section{CONCLUSION}

In conclusion, although COVID-19-associated meningoencephalitis is a rare condition, in a pandemic context, meningitis or encephalitis must be suspected in acute neurological conditions. Herein, we presented a case of COVID-19-associated meningoencephalitis in Brazil, with a favorable prognosis. This case is unique and provides evidence of neurological complications associated with COVID-19. More studies are necessary to fully understand the clinical implications of this rare neurological complication. Physicians should be aware of this diagnosis.

\section{ACKNOWLEDGMENTS}

The authors would like to acknowledge the patient and all the staff from Hospital Sao Jose de Doenças Infecciosas.

\section{AUTHORS' CONTRIBUTIONS}

FJCS and LABGF: manuscript conception and writing; FM, PELH and FRN: data collection, manuscript review and supervision; LSD: manuscript write, revision, supervisionand approved the final version.

\section{FUNDING}

\section{None}

\section{REFERENCES}

1. Zhou P, Yang XL, Wang XG, Hu B, Zhang L, Zhang W, et al. A pneumonia outbreak associated with a new coronavirus of probable bat origin. Nature. 2020;579:270-3.

2. World Health Organization. WHO Director-General's opening remarks at the media briefing on COVID-19: 11 March 2020. [cited 2022 Jan 18]. Available from: https://www.who.int/ director-general/speeches/detail/who-director-general-sopening-remarks-at-the-media-briefing-on-covid-19---11march-2020

3. Jiang F, Deng L, Zhang L, Cai Y, Cheung CW, Xia Z. Review of the clinical characteristics of Coronavirus disease 2019 (COVID-19). J Gen Intern Med. 2020;35:1545-9.

4. Guzik TJ, Mohiddin SA, Dimarco A, Patel V, Savvatis K, MarelliBerg FM, et al. COVID-19 and the cardiovascular system: implications for risk assessment, diagnosis, and treatment options. Cardiovasc Res. 2020;116:1666-7.

5. Moriguchi T, Harii N, Goto J, Harada D, Sugawara H, Takamino $\mathrm{J}$, et al. A first case of meningitis/encephalitis associated with SARS-Coronavirus-2. Int J Infect Dis. 2020;94:55-8.

6. Lai CC, Ko WC, Lee PI, Jean SS, Hsueh PR. Extra-respiratory manifestations of COVID-19. Int J Antimicrob Agents. 2020;56:106024.

7. Montalvan V, Lee J, Bueso T, De Toledo J, Rivas K. Neurological manifestations of COVID-19 and other coronavirus infections: a systematic review. Clin Neurol Neurosurg. 2020;194:105921.

8. Corman VM, Landt O, Kaiser M, Molenkamp R, Meijer A, Chu DK, et al. Detection of 2019 novel coronavirus (2019-nCoV) by real-time RT-PCR. Euro Surveill. 2020;25:2000045.

9. Centers for Disease Control and Prevention. CDC's diagnostic test for COVID-19 only and supplies. [cited 2022 Jan 18]. Available from: https://www.cdc.gov/coronavirus/2019-ncov/ lab/virus-requests.html

10. Puccioni-Sohler M, Poton AR, Franklin M, Silva SJ, Brindeiro R, Tanuri A. Current evidence of neurological features, diagnosis, and neuropathogenesis associated with COVID-19. Rev Soc Bras Med Trop. 2020;53:e20200477.

11. Baig AM, Khaleeq A, Ali U, Syeda H. Evidence of the COVID-19 virus targeting the CNS: tissue distribution, host-virus interaction, and proposed neurotropic mechanisms. ACS Chem Neurosci. 2020;11:995-8.

12. Mondal R, Ganguly U, Deb S, Shome G, Pramanik S, 
Bandyopadhyay D, et al. Meningoencephalitis associated with COVID-19: a systematic review. J Neurovirol. 2021;27:12-25.

13. Packwood R, Galletta G, Tennyson J. An unusual case report of COVID-19 presenting with meningitis symptoms and shingles. Clin Pract Cases Emerg Med. 2020;4:316-20.

14. Dharsandiya M, Shah K, Patel K, Patel T, Patel A, Patel A. SARSCoV-2 viral sepsis with meningoencephalitis. Indian J Med Microbiol. 2020;38:219-21.

15. Bernard-Valnet R, Pizzarotti B, Anichini A, Demars Y, Russo E, Schmidhauser M, et al. Two patients with acute meningoencephalitis concomitant with SARS-CoV-2 infection. Eur J Neurol. 2020;27:e43-4.

16. Ferreira C, Correa-Roda M. Acute meningoencephalitis as initial presentation of SARS-CoV-2 infection in pediatrics. Pediatr Infect Dis J. 2020;39:e386-7.
17. Dugue R, Cay-Martínez KC, Thakur KT, Garcia JA, Chauhan LV, Williams SH, et al. Neurologic manifestations in an infant with COVID-19. Neurology. 2020;94:1100-2.

18. Regev T, Antebi M, Eytan D, Shachor-Meyouhas Y, Ilivitzki A, Aviel YB, et al. Pediatric inflammatory multisystem syndrome with central nervous system involvement and hypocomplementemia following SARS-COV-2 infection. Pediatr Infect Dis J. 2020;39:e206-7.

19. Al-Olama M, Rashid A, Garozzo D. COVID-19-associated meningoencephalitis complicated with intracranial hemorrhage: a case report. Acta Neurochir (Wien). 2020;162:1495-9.

20. Chaumont H, Etienne P, Roze E, Couratier C, Roger PM, Lannuzel A. Acute meningoencephalitis in a patient with COVID-19. Rev Neurol (Paris). 2020;176:519-21. 